\title{
LATLAUNCH AIR-LAUNCH SYSTEM FOR LOW-COST LAUNCHING OF SMALL SATELLITES INTO LOW EARTH ORBIT
}

\author{
Aleksandrs URBAHS (D) ${ }^{1}$, Sergey KRAVCHENKO (i) ${ }^{2}$, Margarita URBAHA (iD) ${ }^{3, *}$, \\ Kristine CARJOVA (D) ${ }^{4}$, Natalja PANOVA (D) ${ }^{5}$, Rafal CHATYS (D) 6 \\ 1-3, ${ }^{5}$ Department of Transport Systems and Logistics, Institute of Aeronautics, Riga Technical University, \\ Lauvas str. 8, Riga, Latvia \\ ${ }^{4}$ Latvian Maritime Academy, Riga, Latvia \\ ${ }^{6}$ Faculty of Mechatronics and Mechanical Engineering, Kielce University of Technology, Kielce, Poland
}

Received 24 October 2019; accepted 03 March 2020

\begin{abstract}
The paper presents the air-launch system enabling the delivery of small satellites into low Earth orbit. One of the most important advantages of the concept is its cost. Generally, the paper proves that launching a carrier from an aerial platform (a movable launch pad) provides the whole range of competitive advantages. In particular, the total losses during the launch from an aerial platform will reduce by $20-35 \%$, and the characteristic velocity of the maneuver will reduce by $4-7 \%$.
\end{abstract}

Keywords: flight safety, LEO satellites, risk, algorithm, air-launch system.

\section{Introduction}

Launching a carrier from an aerial platform is the first step on the way to providing cost-effective delivery of microsatellites into LEO. The demand for launching spacecraft into the Earth's orbit is constantly growing and becoming market-oriented.

In 1985 only 37 out of 253 launched spacecraft were civilian satellites mainly owned by government institutions (United Nations Office for Outer Space Affairs (UNOOSA) Online Index of Objects Launched into Outer Space), while, according to the data of the Union of Concerned Scientists, 1957 satellites were operated by the end of 2018 (Grego, 2019), and this number increased to 2062 by 31 March 2019 (Union of Concerned Scientists, 2005) (994 satellites by the end of 2012 (Satellite Industry Association, 2017), 1459 satellites in 2016 (Satellite Industry Association, 2017), over 51\% of them are privately owned and only $21 \%$ are military or dualpurpose satellites (Satellite Industry Association, 2017; Pixalitics Ltd, 2018).

About $70 \%$ of newly launched satellites are light vehicles below $1200 \mathrm{~kg}$, which are launched to LEO; and the proportion of this group tends to grow, while the average mass of a spacecraft tends to decrease (Satellite Industry Association, 2017).
It is generally accepted that the cost of a launch is the main limiting factor to the commercial exploration of near-Earth space. The cost of launching a big (approx. 4 tons) satellite into LEO is on average 30000 to 40000 EUR per kilo, and the cost of launching a small vehicle weighing up to 100 kilos may exceed 70000 EUR per kilo (Jones, 2018).

Presently only 9 countries in the world, except ESA member countries, own carriers capable of delivering payload into the Earth's orbit: USA, Russia, Ukraine, Japan, India, PRC, Israel, North Korea and Iran.

\section{Project idea}

Attempts to create low-cost carriers are being made mainly by private companies in the USA and Japan: RocketLab (Electron) and SpaceX (various modifications of Falcon); IHI Aerospace (Epsilon, SS-520) and Mitsubishi Heavy Industry N-II.

However, in terms of conceptual approaches and main structural solutions, the proposed carriers do not differ fundamentally from those developed in the 1960's-1970's.

The Institute of Aeronautics (AERTI) of Riga Technical University is developing a LatLaunch aerospace system for launching small satellites into LEO.

${ }^{*}$ Corresponding author. E-mail: margarita.urbaha@rtu.lv 
The aim of this project is to create a commercial launch system for delivering one kilo of payload into LEO at the lowest possible cost. The research shows that the declared aim can be achieved through the following activities:

1) to discard the first and probably the second stage of the traditional carrier rocket substituting them with reusable aircraft and aircraft rocket stages;

2) to use wing lift to the maximum to overcome the force of gravity;

3) to use atmospheric air to the maximum as an oxidant to reach maximum velocity and altitude;

4) to use aerodynamic control up to the maximum possible altitude to save control engine fuel and to discard the control of the thrust vector and correcting engines of the first stage;

5) to use an aerial platform for the launch, which will allow to carry out the launch over free or desert areas of the world ocean and perform the functions of a tracking station and a command and measurement complex at the moment of launching and during the delivery.

Preliminary mission concept is shown in Figure 1.

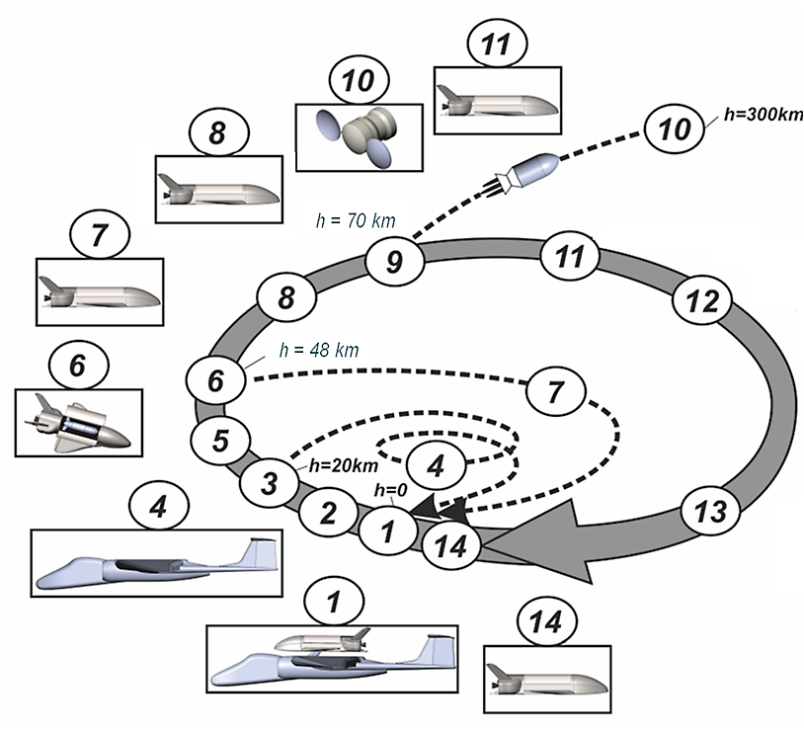

Figure 1. Preliminary LatLaunch launching system mission concept

In Figure 1: 1 - Take-off; 2 - Climb; 3 - Launch of the $2^{\text {nd }}$ stage; $4-1^{\text {st }}$ Stage mission control flight and landing; 5 - Supersonic / hypersonic stage(s) acceleration; 6 - Rocket plane stage launching; 7 - Supersonic / hypersonic stage(s) deceleration, descending and landing; 8 - Rocket plane stage acceleration; 9 - Rocket stage (or mini-shuttle) launching; 10 - Satellite separation; 11 - Rocket plane deceleration; 12 - Rocket plane aviation-type flight and descending; 13 - Rocket plane landing; 14 - System repair and start preparation.

\section{Scheme of launching a satellite orbiting system from an aerial platform}

At the earliest stage of LatLaunch system concept development, it was necessary to correctly make the first decision that would determine the further development of the low-cost launch system design. It was a decision about the place from which the carrier would be launched: from Earth like at standard launch sites, from a sea carrier like in Sea Launch project or from an aerial carrier like in the world's first private launch system called Pegasus (Orbital ATK - Northrop Grumman, USA).

One of the substantial negative factors during the launch from a ground-based launch site is the necessity of evacuating a large area for the whole launch period to avoid victims and destruction in case of possible emergency launch (Gapiński \& Stefański, 2014; Stefański et al., 2014). In addition to that, a ground-based launch site (a launch pad) is costly due to the necessity of acquiring a large plot of land for the launch complex itself including a sufficient safety area around it and other above-ground structures (a refuelling complex with a storage facility for propellant components located at a safe distance from other facilities, an assembly and testing facility, a launch control centre, a command and measurement complex, etc.).

The problems related to the evacuation and securing of large areas, acquisition of a large plot of land and ensuring ground infrastructure was solved in Sea Launch project. A ship, which is used an assembly and testing facility, a launch control centre and a command and measurement complex, tows a launch pad created on the basis of a drilling platform and combined with a refuelling complex. They sail to the near-equatorial area of the world ocean, which is free from maritime traffic, and launch the carrier. In 1999 this project allowed to substantially increase the availability of space launches and reduce the costs.

However, is the sea launch the most effective way of launching?

The analysis shows the opposite. Launching a carrier from an aerial platform, i.e. a movable launch pad, has a whole range of competitive advantages.

Firstly, with a sufficient flight radius of the "platform aircraft", the carrier can be safely launched above the desert areas of the world ocean, while all the required assembly and testing infrastructure of the system is located in densely populated areas of Europe - places where the personnel permanently reside and work. This solution will substantially reduce not only the expenses for the construction of above-ground launch structures but also business travel expenses and infrastructure expenses related to the operation of such a system.

The choice of a certain launch area can be made several days before the launch, which excludes long and costly procedures of informing and securing the launch area and helps to reduce the related expenses.

Secondly, the use of an aerial platform is related to a number of technical and economic advantages of such a launch system. It is explained by the factors listed below. 


\section{Determining the parameters of launching a satellite orbiting system from an aerial platform}

To launch a satellite into LEO with a velocity $V_{\text {sat }}$, the carrier must develop a characteristic velocity of orbital manoeuvre $\Delta V$ that considerably exceeds $V_{\text {sat }}$; the velocity $V_{\text {sat }}$ is the same for all types of launching, it is set through calculations when determining the payload (satellite) target orbit, and in the case of the Earth's orbits the velocity $V_{\text {sat }}$ lies within the range between the first cosmic velocity of $7.8 \mathrm{~km} / \mathrm{s}$ and the second cosmic velocity (escape velocity) of $11.2 \mathrm{~km} / \mathrm{s}$ :

$$
\Delta V=V_{\text {sat }}+\Delta V_{g}+\Delta V_{a}+\Delta V_{c}+\Delta V_{p} \pm \Delta V_{\text {rot }}
$$

where: $\Delta V$ - vector value of the required launcher velocity; $V_{\text {sat }}$ - required orbit velocity of the satellite; $\Delta V_{g}$ - gravity velocity losses; $\Delta V_{a}$ - aerodynamic resistance velocity loses (drag loses); $\Delta V_{c}$ - velocity loses for the transformation of initial speed vector direction to the required orbit velocity vector direction (control velocity loses or steering velocity loses); $\Delta V_{p}$ - velocity losses for the compensation of engine thrust reduction in the atmosphere (engine pressure losses, compensating atmospheric pressure); $\Delta V_{\text {rot }}$ projectioin of the Earth's rotation velocity vector.

The value of the modulus of velocity increment vector is a determining value in the calculation of the required propellant mass and necessary stage/system engine characteristics when solving an inverse problem - Tsiolkovsky equation:

$$
\frac{M_{i}}{M_{f}}=e^{\frac{\Delta V}{V_{e}}},
$$

where: $V_{e}$ - working body exhaust velocity, $\mathrm{m} / \mathrm{s} ; M_{i}$ - initial launching system/stage mass, $\mathrm{kg} ; M_{f}$ - final launching system/stage mass, kg.

To compare the values of velocity losses in (1), let us consider Table 1 (Humble et al., 1995) where velocities are presented in $\mathrm{m} / \mathrm{s}$.

To determine the most efficient method of launching, let us analyse the functional dependencies of values determining the characteristic velocity $\Delta \mathrm{V}$ in accordance with (1) for various methods of launching.

To perform the analysis, we will use the integration of the relevant part of the motion equation in terms of time, taking into account that the flight time $t_{\text {fin }}$ is the useful motion of the carrier; the useful motion occurs from the point of launch 0 to the point of payload separation (or stage separation if the calculation is performed for a stage) $t_{\text {fin }}$.

The value of velocity losses for compensating the engine thrust reduction in the atmosphere (engine pressure losses, compensating atmospheric pressure), which is not presented in Table 1, is maximum for a launch at sea level altitude. It is possible to determine $\Delta \mathrm{V}_{\mathrm{p}}$ in a way described below.

An expression for rocket engine thrust at sea level $\mathrm{T}$ has the following form:

$$
\mathrm{T}=-V_{e} \cdot \frac{d M_{i}}{d t}+\left(P_{a}-P_{e}\right) \cdot S_{a,}
$$

where: $P_{a}$ - atmospheric pressure; $P_{e}$ - pressure of thruster outgoing gases in vacuum conditions at the nozzle end; $S_{a}$ - cross section area of the nozzle end.

Rocket engines used for the first stages of rocket carriers usually have combustion chamber pressures of about $20 \mathrm{MPa}$ and nozzle expansion ratios (the ratio of the crosssection areas and critical section) within the range of 75 to 80 . Thus, the working fluid pressure at the end of the engine nozzle in vacuum is 0.25 to $0.27 \mathrm{MPa}$, and at sea level it is resisted by an atmospheric pressure of $0.1013 \mathrm{MPa}$.

Let us determine the value of velocity loses due to counterpressure on the example of Saturn V carrier rocket (NASA, 1995).

The thrust of Rocketdyne F-1 engine of the first stage (with a total of 5 engines of the stage) at sea level is $\mathrm{T}=6770 \mathrm{kN}$, while in vacuum it is $\mathrm{T}_{v}=7776 \mathrm{kN}$ (NASA, 2014). The difference in thrust $\Delta \mathrm{T}=T-\mathrm{T}_{v}$ is $1006 \mathrm{kN}$ at sea level.

In accordance with Table 4-1 (NASA, 1995), Saturn V reached a velocity of Mach 1 at an altitude of $7800 \mathrm{~m}$ in 65 seconds after launching. Based on the data of the U.S. Standard Atmosphere, 1976, the sound velocity at an altitude of $7800 \mathrm{~m}$ is $308.91 \mathrm{~m} / \mathrm{s}$, the atmospheric pressure is $366.92 \mathrm{mbar}$, the ratio between the pressure at this altitude and pressure at sea level is 0.36212 . Thus, in 65 seconds the flight velocity was $309 \mathrm{~m} / \mathrm{s}$, and the difference in thrust at an altitude of $7800 \mathrm{~m} \Delta \mathrm{T}_{1}=T_{1}-\mathrm{T}_{v}$ was $364.3 \mathrm{kN}$.

The total operating time of the engines of the 1st stage was 160 seconds. Thus, a final velocity of $2388.9 \mathrm{~m} / \mathrm{s}$ was reached at an altitude of $68400 \mathrm{~m}$ where the atmospheric pressure was $0.065465 \mathrm{mbar}$, the ratio between the pres-

Table 1. The value of losses for various launch systems

\begin{tabular}{|l|c|c|c|c|c|c|c|}
\hline \multicolumn{1}{c|}{$\begin{array}{c}\text { Launch } \\
\text { vehicle }\end{array}$} & $\begin{array}{c}\text { Orbit: } \mathrm{h}_{\mathrm{p}} \times \mathrm{h}_{\mathrm{a}}(\mathrm{km}) / \\
\text { inclination }(\mathrm{deg})\end{array}$ & $\begin{array}{c}\text { Vsat } \\
\mathrm{LEO}\end{array}$ & $\Delta \mathrm{Vg}$ & $\Delta \mathrm{Va}$ & $\Delta \mathrm{Vc}$ & $\Delta \mathrm{Vrot}$ & $\Delta \mathrm{V}$ \\
\hline Ariane A-44L & $170 \times 170 / 70$ & 7802 & 1576 & 135 & 38 & -413 & 9138 \\
\hline Atlas 1 & $149 \times 607 / 27.4$ & 7946 & 1395 & 110 & 167 & -375 & 9243 \\
\hline Delta 7925 & $175 \times 319 / 33.9$ & 7842 & 1150 & 136 & 33 & -347 & 8814 \\
\hline Space Shuttle & $196 \times 278 / 28.5$ & 7794 & 1222 & 107 & 358 & -395 & 9086 \\
\hline Saturn V & $176 \times 176 / 28.5$ & 7798 & 1534 & 40 & 243 & -348 & 9267 \\
\hline Titan IV/ Centaur & $157 \times 463 / 28.6$ & 7896 & 1442 & 156 & 65 & -352 & 9207 \\
\hline
\end{tabular}


sure at this altitude and the pressure at sea level equalled to 0.000064609 and the difference in thrust $\Delta \mathrm{T}_{2}=T_{2}-\mathrm{T}_{v}$ was $0.067 \mathrm{kN}$.

According to NASA, 2014, the propellant mass flow for the engines of the first stage was $13011.3 \mathrm{~kg} / \mathrm{s}$. Therefore, with a system launch mass of $2970 \mathrm{t}, 845700 \mathrm{~kg}$ of propellant were used during 65 seconds of flight, and the mass of the remaining propellant was $2124300 \mathrm{~kg}$. The average mass of the system was $2547000 \mathrm{~kg}$. During 160 seconds of flight, $2081808 \mathrm{~kg}$ of propellant were used, and the average mass of the system was $1929096 \mathrm{~kg}$.

Then

$$
\Delta V_{p}=\int_{0}^{t} \frac{\Delta T(t)}{M(t)} d t,
$$

where $M(t)$ is the function of launch system mass change.

It is possible to receive an approximate value of expression (4) through the mean values obtained for 160 seconds of flight: the mean value of thrust difference $503034 \mathrm{kN}$ and the mean value of system mass $1929096 \mathrm{~kg}$. As a result, the design value of velocity losses due to counterpressure will be $41.7 \mathrm{~m} / \mathrm{s}$. It can be affirmed that the received value is close enough to the truth because the function of atmospheric pressure value related to altitude is determined by an exponential dependence, while the counterpressure appears at an altitude of $48000 \mathrm{~m}$ as $0.1 \%$ of the value at sea level. At the same time, as the operation of the stage is coming to an end, the acceleration is increasing reaching a maximum of $38.97 \mathrm{~m} / \mathrm{s}^{2}$ in the 160th second of the flight due to the burnout of propellant reserves - with a value of $10 \mathrm{~m} / \mathrm{s}^{2}$ at the point of launching. An altitude of $48000 \mathrm{~m}$ is reached approximately 22 seconds before the end of the flight, when $86 \%$ of the flight time have elapsed.

Thus, the total counterpressure losses may reach $30-40 \mathrm{~m} / \mathrm{s}$, taking into account that $60-70 \%$ of this value are related to altitudes up to $10-12 \mathrm{~km}$ from the point of launching. Consequently, when launching from an aerial platform, velocity losses will reduce by $18-28 \mathrm{~m} / \mathrm{s}$ at an altitude of $10-12 \mathrm{~km}$.

The gravity losses $\Delta \mathrm{V}_{\mathrm{g}}$ determine the increase of characteristic velocity required for supporting the carrier within the gravitational field (velocity losses due to the effect of gravity).

$$
\Delta V_{g}=\int_{0}^{t_{f i n}} g \sin \theta d t,
$$

where: $\mathrm{g}$ - gravitational acceleration; $\theta$ - angle between the launcher trajectory and horizon.

The value of this integral can be determined as follows:

$$
\Delta V_{g}=(g \cdot \sin \theta)_{\mathrm{miv}} \cdot t_{\text {fin }}
$$

where: $(\mathrm{g} \cdot \sin \theta)_{\text {miv }}-$ mean integral value by flight time.

Thus, gravity losses depend on the value of free fall acceleration, average flight path curvature (more exactly, on the degree of proximity to the horizontal flight and flight time).
Free fall acceleration acting on a launch system mainly depends on the latitude of the launch site and the distance from the Earth's surface. According the GRS80 (Geodetic Reference System, 1980) adopted by XVII General Assembly of the IUGG, Canberra, 1979, the gravitation acceleration can be approximately calculated as:

$$
\begin{aligned}
& g=9,780327 \cdot\left(1+0,0053024 \cdot \sin ^{2}(\varphi)-\right. \\
& \left.0,0000058 \cdot \sin ^{2}(2 \cdot \varphi)\right)-0,000003086 \cdot h,
\end{aligned}
$$

where: $\varphi$ - geographic latitude; $h$ - height above sea level (m).

So, when carrying out a launch from an aerial platform at an altitude of $10 \mathrm{~km}$ under other equal conditions, the reduction of gravity losses will make up $0.315 \%$ when compared to a ground start. At an altitude of $12 \mathrm{~km}$ it will be $0.379 \%$, which will make up $4.4 \mathrm{~m} / \mathrm{s}$ to $5.25 \mathrm{~m} / \mathrm{s}$ if applied to the mean value of this characteristic $(1386.5 \mathrm{~m} / \mathrm{s})$, presented in Table 1.

Actually, the effect will be substantially higher because during a vertical launch $\sin \theta=1$ and during a horizontal launch $\sin \theta=0$.

In addition to that, it is obvious that with all else being equal, the flight time in case of launching from an aviation platform will decrease. Being at an altitude of 10 $12000 \mathrm{~m}$, a platform will help to reduce the flight time by the value required for reaching this altitude. Moreover, an aerial platform itself has some initial velocity, which will allow to save the flight time by the value of time required for reaching such a velocity.

The value $\Delta V_{a}$ characterizing aerodynamic losses is conditioned by thrust consumption for overcoming the force caused by atmospheric air flow. During the acceleration of a carrier rocket, the force of air resistance is the most significant value.

The force of air resistance $\mathrm{F}_{\mathrm{a}}$ is determined as follows:

$$
F_{a}=1 / 2 \cdot \rho \cdot v^{2} \cdot C_{x} \cdot S \text {, }
$$

where: $\rho$ - air density; $v$ - carrier velocity relative to the flow of air (the effect of wind can be neglected as the wind speed is too low relative to the carrier velocity; so, this term will be equal to the carrier velocity relative to the Earth); $C_{x}$ - aerodynamic drag coefficient; $S$ - characteristic section area (the normal carrier section to the carrier velocity vector relative to the air flow).

In this case, the air density can be expressed based on the ideal gas equation:

$$
\rho=\frac{P \cdot M}{R \cdot T},
$$

where: $P$ - absolute atmospheric pressure; $T$ - absolute atmospheric temperature; $R$ - ideal gas constant; $M$ - air molar mass.

In compliance with the U.S. Standard Atmosphere, 1976, in the troposphere the temperature $T$ and pressure $P$ change along with the increase of altitude according to the following dependencies:

$$
T=T_{0}-L \cdot h,
$$

where: $T_{0}$ - standard temperature at sea level (altitude $\left.h=0, T_{0}=288.15 \mathrm{~K}\right) ; L-$ temperature lapse rate $=$ 
$6.5 \mathrm{~K} / \mathrm{km}$ for altitudes up to $11 \mathrm{~km}$, then $L=0 \mathrm{~K} / \mathrm{km}$ up to an altitude of $20 \mathrm{~km}$, after which $L=-1 \mathrm{~K} / \mathrm{km}$ up to an altitude of $32 \mathrm{~km}$ (U.S. Standard Atmosphere, 1976); $h$ - altitude above sea level, $\mathrm{km}$.

$$
P=P_{0}\left(1-\frac{L \cdot h}{T_{0}}\right)^{\frac{g \cdot M}{R \cdot L}}
$$

where: $P_{0}$ - pressure at sea level; $g$ - acceleration due to gravity at sea level.

Thus:

$$
\rho=\frac{M \cdot P_{0}\left(1-\frac{L \cdot h}{T_{0}}\right)^{\frac{g \cdot M}{R \cdot L}}}{R \cdot\left(T_{0}-L \cdot h\right)} .
$$

The U.S. Standard Atmosphere (1976), assumes the following values of constants contained in expressions 4-7: $P_{0}=101325 \mathrm{~Pa}$, sea level standard pressure; $T_{0}=288.15 \mathrm{~K}$, sea level standard temperature $\left(15^{0} \mathrm{C}\right) ; g=9.80665 \mathrm{~m} / \mathrm{s}^{2}$, gravitational constant; $L=6.5 \mathrm{~K} / \mathrm{km}$, temperature lapse rate; $\mathrm{R}=8.31432 \mathrm{~J} / \mathrm{mol} \cdot \mathrm{K}$, gas constant; $\mathrm{M}=28.9644 \mathrm{~g} /$ mol, molecular weight of dry air.

When using the values of the specified constants, expression (12) acquires the following form, which is true up to an altitude of $11 \mathrm{~km}$ (the density is expressed in grams per cubic metre):

$$
\rho \frac{2.93482 \cdot 10^{6}-(0.02256 \cdot h)^{5.2559}}{2395.7713-54.04308 \cdot h} .
$$

It is obvious that the density decreases as the altitude grows. The value of degree index in the numeral of expression (7) for altitudes from $11 \mathrm{~km}$ to $20 \mathrm{~km}$ will increase up to 34.163194 . Thus, the density drop rate will increase along with the increase of altitude.

Based on the data in the U.S. Standard Atmosphere (1976), the air density at sea level is $1.2250 \mathrm{~kg} / \mathrm{m}^{3}$, while at geometric altitudes of $10 \mathrm{~km}, 11 \mathrm{~km}$ and $12 \mathrm{~km}$ the density is $0.41351 \mathrm{~kg} / \mathrm{m}^{3}, 0.36480 \mathrm{~kg} / \mathrm{m}^{3}$ and $0.31194 \mathrm{~kg} / \mathrm{m}^{3}$ respectively.

Thus, in accordance with equation (8), with all else being equal, the aerodynamic drag force during the launch of a carrier at an altitude of $12 \mathrm{~km}$ will decrease by 3.927 times in comparison with the drag force during the launch from the Earth's surface at sea level.

As the aerodynamic drag force $F_{a}$ is equal to the product of the launch system mass $M_{l}$ and acceleration gained by the launch system under the action of this force $a_{a}$,

$$
F_{a}=M_{1} \cdot a_{a} \text {. }
$$

Thus:

$$
a_{a}=\frac{\rho \cdot v^{2} \cdot C_{x} \cdot S}{2 \cdot M_{1}}
$$

The value of velocity losses due to the effect of aerodynamic drag can be obtained by integrating the expression for $a_{a}$ in terms of the time of action of this force. For the period of time $\Delta t$, it is expressed as follows:

$$
\Delta V_{a}=\int_{0}^{\Delta t} a_{a}(t) d t .
$$

It is obvious that as a result of deriving equation (14) in the form of a time dependence for the integration in (15), there will appear 3 terms that depend on the time of action of the force, i.e. on the flight time. These are velocity, altitude (in the expression for air density) and launch system mass. However, there (12) is a tendency for $\Delta V_{a}$ to decrease along with the increase of the launch altitude (decrease of air density), which can be proved, for example, through comparing expressions (15) for altitudes $0 \mathrm{~km}$ and $12 \mathrm{~km}$ when $\Delta t \rightarrow 0$ (with a small change of altitude).

Then the air density is set as a constant and factored out of the integral:

$$
\Delta V_{a, \Delta t \rightarrow 0}=\rho \cdot \frac{C_{x} \cdot S}{2} \int_{0}^{\Delta t \rightarrow 0} \frac{v^{2}(t)}{M_{t}(t)} d t .
$$

This allows to conclude that with all else being equal the initial value of velocity losses due to aerodynamic drag during the launch from Earth at sea level will be 3.927 times higher than that during the launch from an altitude of $12 \mathrm{~km}$.

Taking into account the data presented in Table 1, it is possible to estimate the decrease of launch system velocity losses due to aerodynamic drag when launching from an aerial platform at an altitude of $10-12 \mathrm{~km}$. A decrease by (90-100) $\mathrm{m} / \mathrm{s}$ can be expected.

When assessing $\Delta V c$, it is necessary to note that during the launch from the surface of the Earth the initial vector of system velocity is normally directed towards the final vector of spacecraft velocity.

In case of launching from an aerial platform, the initial and final velocity vectors are collinear.

The launch from an aerial platform implies the absence of control losses related to the alteration of the rocket flight path from the vertical plane to the horizontal one.

In addition to that, during the launch from Earth when the latitude of the launch point is fixed, control losses are related to the necessity of carrying out a turn to alter the flight path of the carrier directing it to the orbit plane at a certain inclination.

During the launch from an aerial platform, the flight path can be altered by the carrier aircraft before the launch system is launched, which reduces the energy consumption of the launch system to zero.

The two above mentioned path manoeuvres as well as the expenditures on flight and path stabilization at the initial stage of flight (compensation of wind load, cloud load, local aerodynamic effects of atmospheric density fluctuations) form a great portion of the value of control losses. So, it is possible to conclude that during the air-launch the value $\Delta$ Vc will decrease by (80-90) \% reducing the velocity losses by $30 \mathrm{~m} / \mathrm{s}$ to $200 \mathrm{~m} / \mathrm{s}$.

In addition to the above listed factors that decrease velocity losses during the launch from an aerial platform 
when compared to the launch from Earth, it is necessary to mention two more factors:

1) firstly, an aerial platform allows to carry out a launch from a region with the minimum acceptable latitude in accordance with the conditions of reaching the satellite flight path in the optimal way, i.e. to use the Earth's rotational velocity to the maximum extent possible;

2) secondly, during the launch from an aerial platform, the initial velocity of the launch system will not equal zero like in case of launching from Earth; it will be equal to the velocity of the aerial platform, i.e. about $230-250 \mathrm{~m} / \mathrm{s}$.

\section{Conclusions}

The analysis allows to conclude that the scheme of launching a satellite orbiting system from an aerial platform has indisputable advantages over a ground launch or a sea launch.

This can be explained with the fact that, in comparison with a ground launch or a sea launch, during the launch from an aerial platform the characteristic velocity of orbital manoeuvre for delivering a satellite into LEO $\Delta V$ decreases by $370 \mathrm{~m} / \mathrm{s}$ at the lowest estimate, while at the highest estimate this decrease may reach over $580 \mathrm{~m} / \mathrm{s}$.

Thus, the total losses during the launch from an aerial platform will decrease by (20-35) \%, and the characteristic velocity of the manoeuvre will decrease by (4-7) \%.

Most losses fall to the 1st stage, which is the heaviest and the most expensive part of the carrier. Therefore, the above specified numbers can be mostly attributed to the first stage of the carrier, for which the characteristic velocity will decrease by (15-25) \% that will make it possible either to start using much cheaper propellants with a lower specific impulse (for example, solid propellants) without detriment to the system mass, or to reduce the propellant reserve and, consequently, the required engine thrust, mass and cost of the launch system.

\section{Acknowledgements}

The authors are grateful for the support of the Latvian Council of Science, within the framework of which Project No. Lzp-2018/2-0344 "Design and modelling of Aerospace System for Launching pico- and nano- Satellites to Low Earth Orbit" the discussed research was performed (project started 01.12.2018, project end date: 31.07.2021).

\section{References}

Gapiński, D. \& Stefański, K. (2014). Control of designed target seeker, used in self-guided anti-aircraft missiles, by employing motors with a constant torque. Aviation, 18(1), 20-27. https://doi.org/10.3846/16487788.2014.865943

Geodetic Reference System. (1980). Adopted by XVII General Assembly of the IUGG, Canberra, 1979.

Grego, L. (2019). Record number of satellites in orbit. Union of Concerned Scientists. https://allthingsnuclear.org/ lgrego/2018satellitedata

Humble, R. W., Henry, G. N., \& Larson, W. J. (1995). Space propulsion analysis and design. McGraw Hill.

Jones, H. W. (2018, 8-12 July). The recent large reduction in space launch cost [Conference presentation]. $48^{\text {th }}$ International Conference on Environmental Systems ICES-2018-81. Albuquerque, New Mexico. https://ttu-ir. tdl.org/bitstream/handle/2346/74082/ICES_2018_81. pdf? sequence $=1$ \&isAllowed $=y$

NASA. (1995). Saturn 5 launch vehicle flight evaluation report, AS-510, Apollo 15 Mission. https://ntrs.nasa.gov/citations/ 19730025086

NASA. (2014). Waking a giant: bringing the Saturn F-1 engine back to life. https://ntrs.nasa.gov/archive/nasa/casi.ntrs.nasa. gov/20140011656.pdf

Pixalitics Ltd. (2018). How many satellites are orbiting the Earth in 2018? https://www.pixalytics.com/sats-orbiting-theearth-2018/

Satellite Industry Association. (2017). State of the Satellite Industry Report. https://www.nasa.gov/sites/default/files/atoms/ files/sia_ssir_2017.pdf

Stefański, K., Grzyb, M., \& Nocoń, Ł. (2014). The analysis of homing of aerial guided bomb on the ground target by means of special method of control. In Petras et al. (Eds.), Proceedings of $15^{\text {th }}$ International Carpathian Control Conference (pp. 551-556), IEEE. https://doi.org/10.1109/CarpathianCC.2014.6843665

United Nations Office for Outer Space Affairs (UNOOSA). (1985). Online index of objects launched into outer space. UNOOSA. https://www.unoosa.org/oosa/osoindex/search-ng.jspx?lf_id=

U.S. Standard Atmosphere. (1976). U.S. Government Printing Office, Washington, D.C. http://ntrs.nasa.gov/archive/nasa/ casi.ntrs.nasa.gov/19770009539.pdf

Union of Concerned Scientists. (2005). UCS Satellite database. https://www.ucsusa.org/nuclear-weapons/space-weapons/ satellite-database 